\title{
ALFABETIZAÇÃO CONSTRUTIVISTA NA PARAÍBA: CONCEPÇÕES E CONTRADIÇÕES DA PRÁTICA PEDAGÓGICA
}

\author{
Maria Aparecida Rosa de Andrade Alixandre ${ }^{(*)}$ \\ Maria das Graças de Almeida Baptista ${ }^{(* *)}$
}

\section{INTRODUÇÃO}

Este estudo tem como objetivo analisar pressupostos da teoria construtivista piagetiana na concepção de professoras no processo de alfabetização. A concepção desses sujeitos sobre a prática pedagógica é analisada à luz do materialismo histórico dialético, que auxilia na compreensão do fenômeno em sua totalidade, destacando sua relação com o meio social e suas possíveis contradições, na tentativa de compreender a teoria no âmbito escolar. O referencial de análise da pesquisa buscou explorar o processo de construção histórica do construtivismo piagetiano, sua inserção na educação brasileira e na concepção e prática de professores do município de João Pessoa.

Nessa vertente, partimos dos estudos de Piaget sobre a epistemologia genética, visto que o termo construtivismo, conforme Macedo (1994), foi utilizado inicialmente por Piaget nos últimos anos de sua produção escrita. Essa teoria destaca que o conhecimento ocorre através de um processo, ou seja, o sujeito constrói seu conhecimento na experiência sobre o objeto. A importância da obra de Piaget é decorrente de sua influência no século XX, principalmente a partir de suas descobertas da psicologia da inteligência.

Piaget não tinha como objetivo criar uma teoria ou um método para educação, mas buscava em seus estudos responder à seguinte pergunta: como o homem constrói conhecimento? Ao longo de sua pesquisa, destacou os processos e etapas de construção da consciência e inteligência, estudou o modo como aprendemos e como conseguimos passar de um nível de conhecimento para outro.

A teoria construtivista chega ao Brasil com o Movimento Escolanovista (esse foi um dos grandes movimentos de renovação da educação brasileira), pautado na adaptação do individuo à

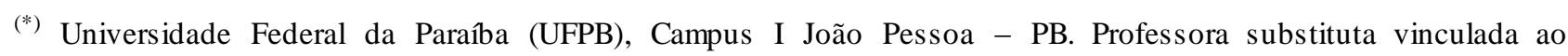
Departamento de Educação Básica. Pesquisadora do Grupo de ÁGORA/UFPB. E-mail: andrade_alcantara2011 @live.com. ORCID: <http://orcid.org/0000-0002-5352-070X>.

${ }^{(* *)}$ Universidade Federal da Paraíba (UFPB), Campus I. João Pessoa - PB. Professora vinculada ao Departamento de Fundamentação da Educação. Líder do Grupo de Estudos e Pesquisa em Filosofia e Psicologia da Educação ÁGORA/UFPB. E-mail: mgabaptista2@yahoo.com.br. <ORCID: http://orcid.org/0000-0003-1084-4269>.
} 
sociedade. Mas esta teoria se difundiu mais intensamente através de dois autores: Emilia Ferreiro e Lauro de Oliveira Lima.

No atual cenário educacional brasileiro, a escola é norteada pela pedagogia do "aprender a aprender". Nessa premissa, o construtivismo piagetiano é pautado no processo adaptativo do sujeito. Assim, em pleno século XXI, é comum encontrar escolas e professores que se afirmam construtivistas. Diante disso, surgem alguns questionamentos: o professor que se autodenomina construtivista conhece, de fato, essa teoria? Quais os pressupostos teóricos que orientam a prática desses docentes? Qual a relação da escola com o posicionamento teórico do professor? Essas são algumas das questões que nos propusemos elucidar por meio desta pesquisa.

A pesquisa empírica foi realizada com dez professoras da Educação Básica no $1^{\circ}$ ano do Ensino Fundamental (Alfabetização), todas formadas no Curso de Pedagogia, que lecionam em escolas municipais de João Pessoa. As participantes da pesquisa se classificam como sujeitos que se autodenominam como adeptos das concepções construtivista piagetiana, eclética ou tradicional. A escolha dos sujeitos iniciou-se pela seleção das escolas. Optamos por dez diferentes escolas localizadas em bairros distintos, selecionando um sujeito em cada escola. Com o intuito de preservar o sigilo em relação à identidade dos sujeitos, estes foram denominados Px, em que $\mathrm{P}$ corresponde a professor, e x ao número, ou seja, P1, P2, P3, P4, P5, P6, P7, P8, P9 e P10, o que equivale a dez professoras participantes da pesquisa.

O presente estudo desenvolveu-se em uma perspectiva qualitativa, tendo como método cientifico o materialismo histórico, que propõe uma historização da problemática estudada, pautada na prática e na relação social dos homens. Como ressalta Triviños (1987, p. 51), “o materialismo histórico é a ciência filosófica do marxismo que estuda as leis sociológicas que caracterizam a vida da sociedade, de sua evolução histórica, da prática social e do desenvolvimento da humanidade". Tal perspectiva teórica perpassa todo o desenvolvimento da pesquisa, iniciando pela trajetória histórica da problemática, ao destacar como a teoria construtivista chega ao Brasil e vem se desenvolvendo no âmbito educacional brasileiro e como se manifesta na concepção das professoras e se objetiva no processo de alfabetização. Nesta perspectiva, temos como método de abordagem o materialismo dialético, considerado a base filosófica do marxismo. Tal método busca uma compreensão dialética do mundo. A escolha por tal metodologia justifica-se por nos propormos um olhar questionador sobre o nosso meio, tanto natural quanto social, destacando o conhecimento como resultado de um processo históricocultural. 


\section{TEORIA PIAGETIANA NA PARAÍBA}

A teoria construtivista se expandiu na Paraîba, inicialmente, pela influência das mudanças que estavam ocorrendo em todo território brasileiro. Vasconcelos (1996, p. 235) aponta que um dos nomes que mais se destaca ao tratar da teoria piagetiana na Paraíba é o de Cleonice Camino, que fez circular essa teoria nos meios acadêmicos de João Pessoa.

A trajetória acadêmica da professora Camino é marcada por aproximações e estudos da teoria piagetiana. No ano de 1965, “conclui a licenciatura em psicologia na Universidade Católica do Recife, logo em seguida fez o curso de teoria e pesquisa em psicologia na Universidade Federal do Pernambuco, cursando a disciplina ministrada por Paulo Rosas". No final da década de sessenta, Camino "foi contemplada com uma bolsa de estudos e viajou para Bélgica para especializar-se em psicologia", e, devido ao seu interesse pela inteligência, "travou um maior contato com as ideias de Piaget" (VASCONCELOS, 1996, p. 235).

Quando a professora Camino retornou ao Brasil, começou a lecionar na Universidade Federal da Paraíba, em João Pessoa. Na época, o Curso de Psicologia somente ainda não tinha sido criado, sendo fundado posteriormente, em 1974, quando passou a lecionar Psicologia do Desenvolvimento, fundamentada na teoria piagetiana.

Ainda segundo Vasconcelos (1996, p. 236), com a amplitude da teoria piagetiana, Camino aprofundou-se no desenvolvimento da moralidade, "culminando, em sua tese de doutorado". Em seus estudos, o aspecto mais explorado da teoria piagetiana foi "o pressuposto 'do conflito como condição necessária para o desenvolvimento moral"”. Entretanto, Camino considera "a teoria piagetiana insuficiente para o tratamento dessa questão".

Junto com Camino, conforme aponta Vasconcelos (1996, p. 236-237), trabalharam outras pesquisadoras, como as "professoras Verônica Luna, na disciplina de Psicologia do Desenvolvimento, e Maria das Graças Cavalcante, na disciplina de Ética”, além de outros profissionais que colaboraram para a "formação do Núcleo Piagetiano da Universidade Federal da Paraíba", como "Marisa Martins, que vem realizando trabalhos em creches, e Maria da Graça Bompastor Dias", e ainda a professora do "Mestrado em Psicologia da Universidade de Pernambuco, que desenvolve trabalhos sobre regras morais e convencionais no raciocínio da criança".

Hoje, Camino é professora aposentada da Universidade Federal da Paraíba, e continua colaborando com orientações em pesquisas de Mestrado e Doutorado. Ao longo de sua caminhada, orientou inúmeras pesquisas e pesquisadores, não somente do curso de Psicologia, como de outros 
cursos, como Matemática, Pedagogia, entre outros, contribuindo com a expansão das ideias de Piaget na Paraíba.

Sem dúvida, a professora Cleonice Camino foi uma das portas de entrada para a expansão das ideias de Piaget no âmbito da Paraíba e, especialmente, na Universidade Federal da Paraíba. No próximo capítulo, iremos tratar do construtivismo piagetiano na alfabetização, destacando alguns fundamentos de uma alfabetização construtivista.

\section{CONSTRUTIVISMO E ALFABETIZAÇÃO}

Antes de tratamos da alfabetização construtivista, é importante retomar a ideia de que Piaget não tinha como objetivo a construção de uma teoria pedagógica, suas pesquisas foram pautadas em compreender o desenvolvimento da inteligência. Contudo, tal teoria veio ao encontro das necessidades educacionais do Brasil na época em que apresentavam altos índices de evasão e fracasso escolar.

Ao tratar da alfabetização, o nome de Ferreiro se destaca, considerando as pesquisas e os inúmeros trabalhos científicos publicados nessa área. A influência de Piaget em seus estudos é revelada pela própria Ferreiro (1987, p. 9), ao destacar que "em todas as minhas apresentações e publicações anteriores tenho afirmado que a teoria de Piaget foi minha principal fonte de inspiração para a pesquisa sobre leitura e escrita”.

No processo de alfabetização, na perspectiva construtivista, a criança é compreendida como um ser que está em constante processo de experiência. Segundo Azenha (1999, p. 59-60), "uma criança, mesmo antes de entrar para a escola, costuma rabiscar utilizando lápis e papel, se tiver oportunidade para isso". Essas primeiras escritas era ignoradas, sendo vistas apenas como rabiscos ou garatujas sem importância.

Se partirmos da teoria piagetiana, "sabemos que as crianças fazem explorações ativas sobre os objetos de conhecimento", uma vez que, "ao escreverem uma palavra ainda não aprendida, colocarão em jogo as concepções que fazem sobre a escrita", estando "em busca de uma resposta para a solução do problema de registrar uma palavra de significado conhecido, mas de forma gráfica ainda obscura" (AZENHA, 1999, p. 60).

Para iniciar um processo de alfabetização, o professor deve "identificar o nível de compreensão que a criança já tem da língua escrita", e planejar as aulas de acordo com o "nível intelectual dos alunos", assim como compreender que mesmo os alunos estando na mesma sala de aula e tento a mesma idade, cada sujeito tem um nível intelectual de desenvolvimento, "o processo 
da aquisição da leitura e da escrita ocorre de maneira individual, sendo um processo de construção da criança” (FERREIRO, 1987, p. 14).

\section{FUNDAMENTOS DE UMA ALFABETIZAÇÃO CONSTRUTIVISTA}

Para que ocorra uma educação construtivista, a finalidade da escola deve ser despertar o interesse, a necessidade e a curiosidade de conhecer e explorar campos desconhecidos. Piaget (1976, p. 79) diz que tal educação dever ser "um processo diário de assimilação e acomodação", sendo os alunos movidos pelo interesse. Nessa perspectiva, "o interesse é uma relação entre necessidades do sujeito e as características do sujeito". Com isso, o "professor é chamado a reestruturar sua ação" no objetivo de atender a essas novas demandas de ensino.

As contribuições das pesquisas de Ferreiro, no âmbito da alfabetização, enfatizaram o papel ativo do sujeito na experiência com o objeto. Tal concepção de sujeito contrapõe a visão anterior de alfabetização pautada em técnicas de ensino.

$\mathrm{Na}$ alfabetização construtivista, o protagonista principal do ensino é o sujeito que está em processo de desenvolvimento, e esse tem seu próprio ritmo de aprendizagem. Como ressalta Azenha (1999, p. 90), “é necessário, portanto, saber que existe um espaço de elaboração do sujeito, mediando ensino e aprendizagem - e nem sempre há correspondência dos percursos de ambos (ensino e aprendizagem)".

Para que o professor possa criar situações favoráveis para a aprendizagem, o seu planejamento deve ser pautado em observações e interpretações das condutas das crianças. Com isso, "conhecer quais são esses processos de compreensão infantil dota o alfabetizador de um valioso instrumento", possibilitando o professor "identificar momentos propícios de intervenção nesses processos e da previsão de quais são os conteúdos necessários para promover avanços no conhecimento" (AZENHA,1999, p. 90-91).

Piaget aponta em seu livro Psicologia e Pedagogia (1980, p. 75), que, para uma aprendizagem construtivista, a educação "exige do mestre um trabalho diferenciado e ativo, enquanto dar lições é menos fatigante e corresponde a uma tendência natural no adulto em geral e no adulto pedagogo em particular". Nessa concepção, deve-se levar em consideração que os professores "encontram-se, cotidianamente, diante de transformações no âmbito educacional, o que requer e acarreta mudanças na forma de ensinar".

Ferreiro (1987, p. 10; 69) destaca, como princípio para uma alfabetização construtivista, "que muito antes de serem capazes de ler", no sentido convencional do termo, "as crianças tentam 
interpretar os diversos textos que encontram a seu redor (livros, embalagens comerciais, cartazes de rua), títulos (anúncio de televisão, estórias em quadrinhos, etc.)”. No processo de alfabetização, alguns problemas cognitivos parecem evidentes, como, por exemplo, que "a criança enfrenta necessariamente problemas de classificação quando procura compreender a representação escrita.

Partindo dos princípios piagetianos, a primeira preocupação do professor de alfabetização em sala de aula deve ser, conforme aponta Brasil (1977. p. 16), criar, no ambiente educacional, condições de assimilação de informações básicas para ensinar ao aluno, isto é, em linguagem mais técnica, "verificar sobre quais esquemas de assimilação se fará a aprendizagem e diligenciar" para todos os alunos aprendam a partir do que dispõe o ambiente, visto que, na vertente piagetiana, "não há condicionamento ou 'associação', mas assimilação do novo pelo antigo: o individuo só recebe o 'estimulo' se estiver preparado recebê-lo. Sensibilização para o estímulo ou esquema de assimilação".

\section{CONSTRUÇÃO DE CONHECIMENTO NA ALFABETIZAÇÃO}

Como já vimos nos capítulos anteriores, o conhecimento, na concepção piagetiana, é resultado de um processo de construção, que parte dos conhecimentos prévios do sujeito. Piaget (1980, p. 45) evidencia que a criança não consegue construir conhecimento "só escutando e vendo algo acontecer", passivamente, ela deve participar dessa construção de forma direta. Ainda que seja na alfabetização, com crianças "pequenas, nenhum sujeito é uma folha em branco", todos têm conhecimentos prévios, adquiridos em experiência anteriores, ainda que esses sejam práticos.

Lima (1980, p. 9) diz que, no processo de aprendizagem, o "verdadeiro educador não ensina fórmulas: cria situações graduais e seriadas que levam a criança a inventar respostas". Ou seja, "educar é promover o desequilíbrio adequado ao nível de desenvolvimento".

Embora Piaget não tenha dado tanta ênfase à alfabetização, suas pesquisas contribuíram para uma perspectiva inovadora. Nessa vertente, um professor construtivista piagetiano em sala de aula, em especial em uma sala de alfabetização, deve ter conhecimento do processo de aprendizagem dos alunos, que ocorre de maneiras distintas. Por exemplo, embora a turma tenha a mesma idade, cada aluno(a) tem suas características individuais na construção do conhecimento.

Aceitar a realidade dos processos de assimilação implica, conforme destaca Ferreiro (1987, p. 69), aceitar também que "aprendizagem alguma começa do zero; o estudo pormenorizado do que a criança traz consigo - sua bagagem de esquemas interpretativos - antes de iniciar o processo de escolarização é essencial - dentro desta perspectiva", para identificar conhecimentos anteriores, ou 
seja, "sobre que bases será possível estimar que tal ou qual informação (apresentada desta ou daquela maneira) será fácil, difícil ou impossível de ser assimilada pela criança”.

Como salientado anteriormente, na perspectiva piagetiana, a construção de conhecimento é pautada na assimilação e acomodação. Segundo Goulart (1987, p. 14), “o desenvolvimento intelectual, controlado por esses dois fatores, processa-se através de todas as atividades infantis", sendo que, "nos dois primeiros anos de vida, as atividades são fisicas, dirigidas a objetos e situações externas", visto que, para a autora, "à medida que aumentam os poderes da criança e ela domina a locomoção, depois a linguagem, as atividades externas desenvolvem uma dimensão interna importante", uma vez que, "o que vai explorando enquanto anda, vai sendo representado mentalmente".

Nessa perspectiva, o processo continua através de todas as atividades infantis. De acordo com Goulart (1987, p. 14), "gradualmente, por volta dos sete anos, surge o pensamento estruturado - inicialmente, as ações interiorizadas, mas que ainda se fundamentam na manipulação mental de objetos constitui as operações concretas", as quais "preparam para um avanço maior, as operações abstratas, que surgiram a partir da adolescência e serão baseadas em um tipo de raciocínio abstrato". Contudo, ainda de acordo com a autora, a "obra de Piaget nos ajuda a compreender a sequencia de desenvolvimento do modelo de mundo que uma criança vai construindo ao longo de cada período de sua vida".

Nessa perspectiva, é interessante apontar os princípios da construção do conhecimento em matemática. Como destaca Brasil (1977, p. X), em matemática, "não só os problemas, mas as próprias explicações dadas pelo professor devem ser apresentadas em forma de situação real (concerte ou imaginada), o que exige do mestre forte dose de imaginação", tais situações-problema devem ser levadas para o cotidiano "simples" da criança e situações concretas.

Contudo, Piaget (1980, p. 154) apresenta um aspecto diferenciador da escola "tradicional e moderna, sendo que a escola tradicional impõe ao aluno a sua tarefa, ela o 'faz trabalhar'". Ele afirma que "sem dúvida a criança pode colocar nesse trabalho uma parte maior ou menor de interesse e de esforço pessoal, e na medida em que o professor é bom pedagogo, a colaboração entre os alunos e ele deixa uma margem apreciável à atividade verdadeira”. Já uma escola construtivista, ao contrário, "apela para a atividade real, para o trabalho espontâneo baseado na necessidade e no interesse pessoal". 


\section{ESTRATÉgIAS PEDAGÓgICAS DE UMA ALFABETIZAÇÃO CONSTRUTIVISTAS PIAGETIANA}

A despeito de a teoria piagetiana não ter sido elaborada para a educação, na época de sua chegada ao Brasil, foi assumida por um grupo de intelectuais, uma vez que atendia às necessidades e aos conflitos no âmbito educacional. Entretanto, baseados na obra piagetiana, outros autores, no Brasil e na América Latina, desenvolveram estudos abordando a educação e, mais especificamente, a alfabetização.

Na década de 1970, Ferreiro desenvolveu estudos que tinham como objetivo compreender o processo de aquisição da língua escrita. Nas décadas de 1980 e 1990, os resultados de suas pesquisas foram temas de debates, encontros, e eventos voltados à educação no Brasil, e seu livro Psicogênese da língua escrita, derivado desses estudos, é considerado o mais influente no âmbito educacional.

Telma Weisz, autora de vários livros acerca da alfabetização construtivista, no Prefácio para o livro Reflexões sobre alfabetização, de Emilia Ferreiro, assim se expressa:

Emília Ferreiro descobriu e descreveu a psicogênese da língua escrita e abriu espaço agora - para um novo tipo de pesquisa em pedagogia. Uma pedagogia onde a compreensão do papel de cada um dos envolvidos no processo educativo muda radicalmente. Suas idéias, quando levadas á práticas, produzem mudanças tão profundas na própria natureza das relações do poder pedagógico que, sonho ou não, é inevitável acalentar a ideia de que esta revolução conceitual sobre a alfabetização acabe levando a mudanças profundas na própria estrutura escolar. (WEISZ, 1993, p. 4-5).

Uma educação e alfabetização construtivista é centrada no objeto de conhecimento. Nesse sentido, Lima (1974, p. 95) assim se expressa: "suponhamos que temos que ensinar a alguém o que é um gato, para tal atividade sistemática, o cientista deve ter partido da analise empíricoexperimental, no caso, através da observação do animal chegando a uma classificação. O autor destaca ainda que, "justamente o contrário: damos a classificação geral e apresentamos o gato como exemplo da espécie, desprezando a ordem genética como o conhecimento se foi sistematizado". Logo, "é evidente que esta definição cobre imenso vazio epistemológico. Nos tratados científicos, pretendemos abreviar o conhecimento, dando longos processos indutivos ou dedutivos, em seu estágio final de organização cientifica, clara violação da ordem das coisas” (LIMA, 1974, p. 95).

Segundo Lima (1974, p. 96), na perspectiva piagetiana, ao ensinar em sala de aula às crianças de alfabetização o que é um gato, por exemplo, deve-se "partir do recurso natural - 
apresentar ao aluno um gato vivo e fazer com que o aluno o observe sobre todos os aspectos"; a partir disso, deve "desenhá-lo, descrevê-lo, dissecá-lo, levá-lo ao Raio X, ao microscópio etc., para depois compará-lo com outros animais e estabelecer as semelhanças e as diferenças".

Como destaca, a construção do conhecimento deve ser pautada na experiência sujeitoobjeto. Afirma Lima (1974, p. 98) que "aprender é manipular”, “quer se entenda por manipulação o manejo concreto dos objetos, quer a discussão das ideias e conceitos num grupo de estudo ou uma simples reflexão. As palavras (em que se baseia o ensino verbalístico) são longínquos fantasmas da realidade". Nesse vertente, "só um gato serve para ensinar o que é um gato, porque só um gato pode ser realmente, manipulado". O autor destaca que "aprender é aplicar sobre o objeto esquemas de assimilação". $\mathrm{Na}$ experiência, o "recurso significativo vale na medida que permite, não apenas perceber (vez que o conhecimento não provém da percepção)", mas "manipular o objeto (qualquer aplicação de esquemas de ação ou de assimilação ao objeto é uma manipulação)".

Assim, de acordo com Lima (1974, p. 98-99), "o objeto é significativo na construção do conhecimento", ou seja, permite não apenas perceber (vez que o conhecimento não provém da percepção), mas manipular o objeto (qualquer aplicação de esquemas de ação ou de assimilação ao objeto é uma manipulação). Logo, “o pensamento - mostra Piaget - provém da ação e não da percepção: esta só é um instrumento de conhecimento quando atinge o nível de atividade perceptiva".

No processo de ensino e aprendizagem, o professor "deve entusiasmar o aluno", de forma que "se sintam motivados a construir seu conhecimento". Ao entusiasmar "os alunos pelo trabalho que está sendo realizado; eles carregarão até pedra se o professor souber entusiasmá-los. Daí a importância didática da capacidade de dramatização do professor” (LIMA, 1976, p. 236).

Nesse processo de construção de conhecimento, o professor deve estimular, elogiar e direcionar a aprendizagem das crianças. Para isso, cabe ao professor se preparar para criar situações e organizar materiais para o aluno passar a construir conhecimento. Lima (1976, p. 236; 304) aponta que se deve "elogiar tudo que for elogiável. O elogio é uma prova de que o aluno está tendo bom êxito. Todos nós queremos ter bom êxito, isto é, auto-realização, auto-afirmação”. Em vez de destacar "erros, o professor deve destacar acertos: o êxito dinamiza o psiquismo". O autor destaca que o "elogio (aprovação) é um reforço do êxito do ponto de vista da estrutura de relação do sujeito com o grupo a que pertence". Logo, "a motivação, pois, pode referir-se à ação em si (independentemente do equilíbrio que esta ação provoca entre o individuo e o grupo) ou pode 
significar pouco como satisfação provinda da ação em si’, para ter grande significado como equilibrio do indivíduo em suas relações de ação com o grupo.

Um processo de alfabetização construtivista está centrado no objeto de conhecimento, nesse caso, a língua escrita. Ferreiro e Teberosky (1985, p. 30) ressaltam que "o caminho em direção a este conhecimento objetivo não é linear: não nos aproximamos dele passo a passo, juntando peças de conhecimento umas sobre as outras, mas sim através de grandes reestruturações globais", com isso, "algumas das quais são 'errôneas' (no que se refere ao ponto final), porém "construtivas" (na medida em que permitem aceder a ele)".

Ferreiro e Teberosky (1985, p. 28-29) apontam que a concepção de aprendizagem, entendida como um processo de obtenção de conhecimento inerente à psicologia genética, supõe a existência de processos de aprendizagem do sujeito.

$\mathrm{Na}$ vertente piagetiana, para elaborar um plano de aula, o professor já deve identificar quais os conhecimentos e esquemas prévios que servirão de "suporte" para a nova aprendizagem. Cabe ao professor, segundo Lima (1976, p. 238), compreender que não "se aprende nada inteiramente novo: basear toda a aprendizagem nova em outra aprendizagem já feita. Ao planejar o próximo período de aprendizagem indicar os esquemas prévios em que apoiará atividade". Logo, “qualquer aprendizagem inicia de um prévio esquema de assimilação (programação). Fazer sempre a sondagem antes de lançar um assunto novo: ou os alunos já sabem e vão-se aborrecer ou estão tão distantes dele e não o compreenderão".

Em sala de aula, o professor tem o papel de orientador e mediador, criando situações para a aprendizagem do aluno. Nessa perspectiva, o professor deve, segundo Lima (1976, p. 239), "colocar-se na classe como um orientador da atividade do aluno". Com objetivo de "fazer os alunos trabalharem - eis o grande mérito do bom professor". Tal papel "lembra o técnico de futebol: quem joga são os jogadores".

O professor "deve atender a cada aluno em sua carteira: o professor está em classe para ajudar os alunos". Logo, "os mais tímidos não teriam coragem de procurá-lo. Circular na classe, participar dos grupos, dirigir-se individualmente a cada aluno" (LIMA, 1976, p. 241).

Segundo Lima (1976, p. 408; 238), “a criança não deve ser educada para copiar e reproduzir o que já existe, para 'comportar-se', para ser conformista, para aceitar os juízos-feitos e a ciênciafeita"; ao contrário, na perspectiva piagetiana, a criança é para "ser livre, responsável, autônoma, de espírito criador". No que se refere a atividades para essa criança ativa, deve inicialmente atrair o 
interesse "com atividades enigmas, estamos sempre dispostos a decifrar 'enigmas'. A inteligência tem como função resolver problemas".

Portanto, o professor deve criar condições para o aluno expor suas ideias. Desse modo, cabe ao professor, segundo Lima (1976, p. 240), ouvir muito o aluno, e falar apenas para orientar a atividade. Logo, o professor deve "usar a imaginação: não se deixar cair na rotina. Um professor rotineiro é insuportável para os alunos e demonstra incapacidade de renovação".

Nesse sentido, vale salientar alguns exemplos práticos de estratégias piagetianas em sala de aula. Para trabalhar a "Conservação de quantidade use recipientes de tamanhos iguais e diferentes", grãos e entre outros materiais, que podem auxiliar na construção de conhecimento da criança. Logo, “a conservação é uma noção operatória que permite à criança compreender que alterações de forma não causam alteração da quantidade, do peso ou do volume", visto que as "crianças em nível préoperatório de desenvolvimento parecem raciocinar apenas sobre estados ou configurações, desprezando as transformações". Nessa vertente, "na fase pré-operacional, a criança é capaz de descentração, isto é, de centrar sua atenção em 2 ou mais aspectos da realidade ao mesmo tempo. Quando focaliza na altura do copo, ela não consegue ficar atenta à sua largura" (GOULART, 1987, p. 62).

Em relação à "conservação de peso", Goulart (1987, p. 65) destaca que "a conservação de peso é uma noção graças à qual a criança compreende que alterações de forma e/ou posição não são acompanhadas de conseqüentes alterações de peso", pois "a conservação de peso é alcançada mais tardiamente do que a conservação de quantidade". O autor destaca ainda que, geralmente, de "oito anos em diante, as repostas infantis tendem a evidenciar o domínio da conservação de peso. Ás vezes, as respostas infantis variam conforme o material usado; provavelmente, isto se deve à familiaridade com o material".

No que se refere à "conservação de volume", Goulart (1987, p. 69) afirma que essa "é uma noção alcançada quando a criança compreende que alterações de forma, posição, diferenças de peso não estão, necessariamente, associadas ás variações de volume"; "essa noção é, geralmente, alcançada por volta de 9-10 anos, mais tardiamente do que a conservação de quantidade e peso. Parece haver uma hierarquia no surgimento desses três tipos de conservação".

Com o objetivo de identificar como seu aluno compreende a noção de número, Goulart (1987, p. 104) destaca experiência destinada a avaliar a noção de unidade. "Mostre à criança pares de objetos - duas bolas, dois carretéis, duas carteiras, dois lápis, etc. e pergunte: O que há de comum em todos estes conjuntos? Ou há alguma coisa em comum quando você observa estes 
conjuntos?". E, ainda, "repita a experiência usando conjuntos de três, quatro objetos e depois de um objeto. E repita a pergunta: o que há de comum em todos estes conjuntos?”.

Nesse processo, a professora deve compreender que, quando a criança "aprender a contar verbalmente não significa que ela tem o domínio do conceito de número". Logo, "a formação do conceito de número" se faz em estreita "conexão com o desenvolvimento das operações lógicas de classificação e seriação". A autora ainda destaca que, "até cerca de 6 anos a criança tem um conceito intuitivo de número e acredita que a quantidade se altera quando se muda a disposição espacial dos elementos". Com isso, "basta espaçar os elementos de um conjunto para a criança julgar que aumentou a quantidade dos elementos", em razão de que "a noção operatória de numero só é possível quando se houver constituído a conservação de quantidades descontínuas, independente dos arranjos espaciais" (GOULART, 1987, p. 35; 109).

Ainda segundo Goulart (1987, p. 15), “o número constitui uma síntese de seriação e da inclusão e exige o domínio dos seguintes princípios: constância, associatividade e reversibilidade”.

Entretanto, só é possível planejar o ensino quando se conhece bem o desenvolvimento da criança e, particularmente, daquela criança a quem se vai ensinar. Nessa perspectiva, Brasil (1977, p. 24-25) conclui que "não devemos esquecer que a aprendizagem é um processo biológico (Piaget) e a embriologia jamais prepara antes o "material" para depois iniciar a "construção", não se distinguindo dela".

Segundo Brasil (1977, p. 19), "devemos tomar providencia para garantir no aluno a percepção plena de situação em que o estamos colocando: linguagem clara, recursos audiovisuais, etc., de modo que ele tem autoconsciência do processo que está envolvido". Nesse sentido, as situações devem estabelecer ligações entre a vivência do aluno e a prática em sala de aula. Com isso, "podemos esperar uma acomodação dos esquemas que servem à resolução dos problemas já dominados pelos alunos, à nova situação, conseguindo-se assim a assimilação da mesma”.

Essa problemática deve ocorrer em sala de aula, com o objetivo de promover a desequilibração e equilibração no processo de construção do conhecimento do aluno. "O problema, portanto, é ter sempre em mente os elementos essenciais da aprendizagem", assim como "ativação ou preparação de esquemas de assimilação", na "percepção clara da situação nova", e na "acomodação dos esquemas ativados a nova situação" (BRASIL, 1977, p. 19).

De acordo com Lima (1976, p. 92), "toda estrutura escolar, em geral, e a organização da classe, em particular, devem permitir aos alunos oportunidades de decisão e de trabalho autônomo, a fim de que ponham eles em exercício permanente sua capacidade de iniciativa e de deliberação", 
pois "só assim aprenderão a se autogovernar e a assumir a responsabilidade por seus atos, como convém a futuros cidadãos de uma democracia".

Nessa vertente, o sujeito tratado nas pesquisas de Piaget "é aquele que procura ativamente compreender o mundo que o rodeia e trata de resolver as interrogações que este mundo provoca". Não sendo um sujeito passivo, o qual "espera que alguém que possui um conhecimento o transmita a ele por um ato de benevolência", posto ser "um sujeito que aprende basicamente através das suas próprias ações sobre os objetos do mundo e que constrói suas próprias categorias de pensamento ao mesmo tempo que organiza seu mundo". Assim, supõe-se que esse objeto cognoscente está também presente na aprendizagem da língua escrita. (FERREIRO; TEBEROSKY, 1985, p. 26).

Como destacado no decorrer desse trabalho, apesar de Piaget não ter apresentado técnicas e métodos para a educação, e tão pouco ter descrito estratégias para a alfabetização, desenvolveu pesquisas e elaborou um corpo teórico que orientou a compreensão acerca do processo de construção de conhecimento, influenciando outras pesquisas e estudos.

\section{CONCEPÇÕES E CONTRADIÇÕES DA PRÁTICA DOCENTE}

A investigação da concepção docente de alfabetização acerca do construtivismo piagetiano, de como o professor compreende tal teoria, revela-se com a entrevista. As informações obtidas revelam que, das dez professoras entrevistas, 5 se denominam construtivistas, 4 ecléticas e 1 tradicional. As professoras PF1, PF3, PF4, PF6 e PF8 se autodenominam construtivistas piagetianas. Elas salientam que fundamentam sua prática em tal teoria. Já as professoras PF5, PF7, PF9 e PF10 enfatizam serem ecléticas, uma vez que fundamentam suas práticas em diferentes teorias e teóricos. Das dez professoras entrevistadas, apenas a PF2 se denomina tradicional, destacando que "o aluno necessita é de conteúdo.

No início da expansão da teoria de Piaget, destacava-se a falta de um aprofundamento teórico dos professores acerca da psicologia e, mais especificamente, acerca do desenvolvimento da inteligência, além do que a apropriação da teoria ocorria de forma fragmentada. Como ressalta Vasconcelos (1996, p. 69), "Piaget declara-se apreensivo com a dificuldade dos psicólogos, no âmbito escolar, e ainda com relação aos educadores, por terem insuficiente formação em psicologia".

O motivo que preocupava Piaget, apesar da distância temporal, é possível de ser identificado, ainda na realidade educacional. Em muitos casos, existe uma confusão teórica que fica evidente na fala da professora PF8, que se denomina construtivista piagetiana: "trabalho com a zona 
de desenvolvimento proximal, a partir daquilo que a criança já sabe para desenvolver novos conhecimentos, prestando atenção à fase de desenvolvimento delas, sensório- motor, pré operatório...". Nessa perspectiva, a professora apresenta princípios de dois teóricos distintos: Vigotsky, com a "zona de desenvolvimento proximal"; e Piaget

- com a "fase do desenvolvimento".

A esse respeito, Vázquez (1968, p. 207) sinaliza que "uma teoria é prática na medida em que materializa, através de uma série de mediações, o que antes só existia idealmente, como conhecimento da realidade ou antecipação ideal de sua transformação".

A professora PF2, apesar de destacar que "em sala de aula não é necessário teorias, que a prática não se relaciona com a teoria", em sua prática, trabalha com a "construção de conhecimento", pressuposto da teoria construtivista. Para o desenvolvimento de sua prática, segundo Piaget (1980, p. 78), deve-se compreender os princípios teórico-metodológicos que a orienta, sendo fundamental ao "planejar uma aula, saber qual objetivo deseja alcançar".

Na perspectiva construtivista, a ação exercida sobre o objeto pode se configurar para alguns como "barulho", "bagunça". A esse respeito, vale salientar a fala da professora PF1, que, com 25 anos de sala de aula e se intitular construtivista piagetiana, destaca não ser compreendida na escola em relação à metodologia que utiliza: "Infelizmente, eu sofro por não ser compreendida. Dizem que meus alunos fazem muito barulho... alteramos a ordem da escola".

Em sala de alfabetização o professor deve iniciar a aula buscando compreender qual o nível de assimilação do aluno, no que se refere ao tema a ser tratado. Cabe ao professor criar condições necessárias para que o aluno busque em seus esquemas anteriores, ou seja, em experiências anteriores, base para assimilar o novo. Segundo Brasil (1977, p. 16), há situações novas que não encontram, nos alunos, esquemas prévios de assimilação. A ação docente, nesses casos, deve começar pela preparação dos referidos esquemas.

A professora PF7, por sua vez, ressalta a necessidade que a sua profissão impõe de buscar se atualizar e de aperfeiçoar o seu conhecimento: "Sou professora, mas me sinto aluna, aprendo junto com meus alunos." Destacando, ainda: "Sempre busquei técnicas novas para trazer, para desenvolver minhas atividades em sala de aula. A questão dos jogos com palitos, uso do material dourado, contagem dos dedos da mão, jogos com tampinhas...”. Já a professora PF8 destaca: “Na matemática tem muitas atividades e possibilidades, como a trilha de matemática, jogando dados, jogos de agrupar palitos. Também exploro muito as atividades de matemática no livro didático (nesse caso, não construtivista em matemática)". 
As professoras trazem, aspectos positivos e negativos do construtivismo em sala de aula. Positivo, uma vez que a construção do conhecimento é considerado algo prazeroso ao aluno. Negativo, porque as professoras parecem considerar que, em pleno século XXI, o trabalho em sala de aula, na perspectiva construtivista, não supre as necessidades de formação para o mercado.

De acordo com as reflexões feitas pelas professoras, existem algumas dificuldades e contradições para tal prática. Como destaca a professora PF5, "Eu acho que se for só o construtivismo em sala, a criança não consegue se desenvolver, não resolver deixar a criança muito solta". Já em sala de aula "tem hora que você tem que 'puxar as rédeas', mas eu tento trazer um pouquinho de cada teórico para minha sala de aula por influência da universidade”.

Vale destacar que, apesar de as concepções das professoras apresentar alguns elementos da teoria construtivista piagetiana, falta um aprofundamento teórico a respeito do desenvolvimento da criança, dos princípios da construção de conhecimento e da liberdade do aluno, enquanto características da teoria de Piaget.

\section{CONSIDERAÇÕES FINAIS}

Nossas proposições conclusivas resultam de reflexões desenvolvidas ao longo da presente pesquisa e que nos permite destacar a necessidade de uma maior compreensão sobre as teorias da educação, especialmente nesse estudo sobre a teoria de Piaget, uma vez que o pouco que se sabe acerca dessa teoria se confunde com outros pressupostos teóricos. Assim, alguns professores se denominam "ecléticos", mas ao serem indagados sobre tais teorias, não conseguem pontuá-las.

Para que o professor atinja uma prática coerente, torna-se necessário ir à teoria e ao seu criador, de forma que suas práticas desenvolvidas em qual nível de ensino estejam teoricamente bem fundamentadas, tanto no conhecimento do conteúdo como nos métodos de ensino. As professoras entrevistadas minimizam o ensino de matemática, como fica claro na fala de uma dela: "faço atividades de matemática apenas uma vez por semana"; outras relacionam apenas a jogos, ou ainda atividades no livro didático, dando ênfase ao ensino das letras.

Nesse sentido, faz-se necessária uma mudança estrutural na educação, partindo da formação do professor. Surge, assim, o questionamento: "Como estão sendo formados os futuros professores?". Cabe um estudo mais aprofundado sobre a formação dos profissionais da educação. Contudo, tal formação docente deve preceder de reformas nas leis que regem a educação no país, posto que tais mudanças não ocorrem, uma vez que não é de interesse político e econômico que tenhamos uma "educação de qualidade", com professores bem renumerados, escolas equipadas com 
materiais didáticos e com estrutura física adequada. Afinal, "educação de qualidade", resultaria em sujeitos autoconstruídos capazes de autogestão, capazes de atuar na transformação do meio e de relacionar-se consigo mesmo e com a coletividade, capazes de se opor a ideologias da classe dominante.

As indagações e angústias compartilhadas de professoras de alfabetização, dificuldades inerentes à articulação da teoria e da prática, mostram que a teoria construtivista piagetiana não atente às atuais necessidades da sociedade capitalista. Afinal, o conhecimento, na vertente capitalista, é tratado como "mercadoria", apresentando contradições com os princípios do conhecimento destacados por Piaget.

\section{REFERÊNCIAS}

AZENHA, Maria da Graça. Construtivismo: de Piaget a Emilia Ferreiro. São Paulo: Ática, 1999.

BRASIL, Luís Alberto S. Aplicação da teoria de Piaget ao ensino da matemática. Colaboração de Lauro de Oliveira Lima. Rio de Janeiro: Forense-Universitária, 1977.

FERREIRO, Emilia. Alfabetização em processo. Trad.: Sara Cunha Lima. São Paulo: Cortez, 1987.

; TEBEROSKY, Ana. Psicogênese da Língua Escrita. Trad.: Diana Myriam Litchtenstein, Liana Di Marco e Mário Corso. Porto Alegre: Artes Médicas Sul, 1985.

GOULART, Iris B. Piaget: Experiências Básicas para Utilização pelo Professor. 4 ed. Petrópolis: Vozes, 1987.

LIMA, Lauro de O. Piaget para principiantes. São Paulo: Summus, 1980.

A escola secundária moderna: organização, métodos e processos. 11. ed. Rio de Janeiro: Forense Universitária, 1976.

Escola no Futuro: orientação para os professores de prática de ensino. 2. ed. Rio de Janeiro: J. Olympio, 1974.

MACEDO, Lino. Ensaios construtivistas. São Paulo: Casa do Psicólogo, 1994.

PIAGET, Jean. Psicologia e Pedagogia. 5. ed. Rio de Janeiro: Forense Universitária, 1980.

. A equilibração das estruturas cognitivas: problema central do desenvolvimento. Trad.: Marion M. S. Penna. Rio de Janeiro: Zahar Editores, 1976.

TRIVIÑOS, Augusto N. S. Introdução à pesquisa em Ciências Sociais: pesquisa qualitativa em educação. São Paulo: Atlas, 1987.

VASCONCELOS, Mário S. A difusão das ideias de Piaget no Brasil. São Paulo: Casa do Psicólogo, 1996.

VÁZQUEZ, Adolfo. S. Filosofia da práxis. Rio de Janeiro: Editora Civilização Brasileira S.A., 1968.

WEISZ, Telma. Prefácio. In: FERREIRO. E. Reflexões sobre a alfabetização. São Paulo: Cortez, 1993. 


\section{RESUMO}

Este artigo, resultante de uma dissertação de Mestrado, analisa elementos da teoria construtivista piagetiana no processo de alfabetização e na concepção de professoras em escolas municipais de João Pessoa/PB. Tal estudo justifica-se no discurso recorrente das professoras a respeito do construtivismo, e pelo pressuposto de diferentes associações feitas pelos professores em relação à teoria e a prática. A metodologia desse estudo desenvolve-se em uma perspectiva qualitativa, o estudo tem como método científico o materialismo histórico. A pesquisa nos permite destacar as contradições na concepção das professoras, assim como a necessidade de uma maior compreensão sobre as teorias da educação, uma vez que o pouco que se sabe acerca dessa teoria se confunde com outros pressupostos teóricos.

Palavras-chave: Teoria construtivista piagetiana. Alfabetização. Concepção docente.

\section{CONSTRUCTIVIST LITERACY IN PARAÍBA: CONCEPTIONS AND CONTRADICTIONS OF PEDAGOGICAL PRACTICE}

\section{ABSTRACT}

This article, resulting from a Masterthesis, analyzes elements of the piagetian constructivist theory in the process of literacy and the conception of teachers in João Pessoa (PB) municipal schools. Such study is justified in the recurrent discourse of the teachers about constructivism, and by the assumption of different associations made by teachers in relation to theory and practice. The methodology of this study is developed in a qualitative perspective, the study has the historical materialism as scientific method. The research allows us to highlight the contradictions in the conception of the teachers, as well as the need for a greater understanding on theories of education, since the little that is known about this theory is co nfused with other theoretical presuppositions.

Keywords: Piagetian constructivist theory. Literacy. Teacher conception.

\section{ALFABETIZACIÓN CONSTRUCTIVISTA EN PARAÍBA: CONCEPCIONES Y CONTRADICCIONES DE LA PRÁCTICA PEDAGÓGICA}

\section{RESUMEN}

Este artículo, resultante de una tesina de Master, analiza elementos de la teoría constructivista piagetiana en el proceso de alfabetización y en la concepción de profesoras en escuelas municipales de João Pessoa/PB. Dicho estudio se justifica en el discurso recorrente de las profesoras respecto al constructivismo, y por el presupuesto de diferentes asociacioneshachas por los profesores en relación a a la teoría y la práctica. La metodología de este estudio desarrolle en una perspectiva calitativa, el estudio tiene como método científico el materialismo histórico. La investigación nos permite poner de relieve las contradicciones en la concepción de las profesoras, así como la necesidad de una mayor comprensión sobre las teorías de la educación, a vez que lo poco que se sabe acerca de dicha teoría se confunde con otros presupuestosteóricos.

Palabras claves: Teoría constructivista piagetiana. Alfabetización. Concepción docente.

Submetido em: 30 de setembro de 2019 Aprovado em: 30 de abril de 2019 